\title{
Psicooncología
}

ISSN: $1696-7240$

\section{The impact of mastectomy on body image and sexuality in women with breast cancer: a systematic review}

\author{
Bárbara Martins Faria ${ }^{1}$; Isabela Martins Rodrigues ${ }^{2}$; Leticia Verri Marquez ${ }^{3}$; Uriel da Silva \\ Pires $^{4}$; Stefan Vilges de Oliveira ${ }^{5 *}$
}

Recibido: 15 de diciembre de 2020 / Aceptado: 1 de marzo de 2021

\begin{abstract}
Objective: The study aims to evaluate the impact of mastectomy on body image and sexuality of women with breast cancer, as well as to provide a general understanding of their quality of life. Method: This review followed the PRISMA guidelines. The expression "Mastectomy AND (sexuality OR "body image")" was searched in Lilacs, Scielo, Pubmed and Scopus databases. Articles published in English, Portuguese and Spanish between 2010 and 2020 were selected. The text analysis was carried out by peers. Results: $69.3 \%$ (43) of the studies presented mastectomy as a technique that worsens body image, sexual functioning and quality of life of women. Less radical procedures, such as breast-conserving surgery, showed lower impact on these indicators. Breast reconstruction is an alternative to mitigate breast surgery impacts. Conclusion: Mastectomy caused the major impacts on body image, sexual functioning and quality of life. These implications need to be considered during therapeutic choice.
\end{abstract}

Keywords: Breast neoplasms, mastectomy, body image, sexuality, quality of life.

\section{[es] El impacto de la mastectomía en la imagen corporal y en la sexualidad de mujeres con cáncer de mama: una revisión sistemática}

Resumen: Objetivo: Evaluar el impacto de la mastectomía en la imagen corporal y sexualidad de mujeres con cáncer de mama, y proporcionar una comprensión general de su calidad de vida. Método: Esta revisión siguió las directrices PRISMA. Se buscó la expresión "Mastectomy AND (sexuality OR "body image")" en las bases de datos Lilacs, Scielo, Pubmed y Scopus. Se seleccionaron artículos publicados en inglés, portugués y español entre 2010 y 2020. Los textos fueron analizados por parejas. Resultados: El 69,3\% (43) de los estudios muestran que la mastectomía empeora la imagen corporal, el funcionamiento sexual y la calidad de vida de las mujeres. Procedimientos menos radicales, como

1 Bárbara Martins Faria - Federal University of Uberlândia. Minas Gerais - Brazil

E-mail: bmartinsfaria@gmail.com

2 Isabela Martins Rodrigues - Federal University of Uberlândia. Minas Gerais - Brazil

E-mail: isabelamartinsr@hotmail.com

3 Leticia Verri Marquez - Federal University of Uberlândia. Minas Gerais - Brazil

E-mail: leticiaverrim@gmail.com

4 Uriel da Silva Pires - Federal University of Uberlândia. Minas Gerais - Brazil

E-mail: uriel.pires@hotmail.com

5 Stefan Vilges de Oliveira - Federal University of Uberlândia. Minas Gerais - Brazil

E-mail: stefan@ufu.br

* Dirección de correspondencia: Department of Collective Health, Faculty of Medicine, Federal University of Uberlândia. Pará Avenue, 1720, Campus Umuarama, Block 2U, Room 8, Umuarama, Zip Code: 38405320. Uberlândia, Minas Gerais - Brazil. E-mail: stefan@ufu.br 
la cirugía conservadora de la mama, mostraron menor impacto. La reconstrucción mamaria puede mitigar los impactos de las cirugías. Conclusión: La mastectomía causó mayores impactos con respecto a imagen corporal, funcionamiento sexual y calidad de vida. Estas implicaciones deben considerarse durante la elección terapéutica.

Palabras clave: Neoplasias de mama, mastectomía, imagen corporal, sexualidad, calidad de vida.

Sumario: 1. Introduction 2. Materials and Methods 3. Results 4. Discussion 5. Conclusion 6. References

Cómo citar: Martins Faria B, Martins Rodrigues I, Verri Marquez L, da Silva Pires U, Vilges de Oliveira S. The impact of mastectomy on body image and sexuality in women with breast cancer: a systematic review. Psicooncología 2021; 18: 91-115. doi: 10.5209/psic.74534

\section{Introduction}

Globally, breast cancer is, excluding non-melanoma skin cancer, the most frequently diagnosed cancer in women, and the commonest cause of cancer death among this group $^{(1)}$. In 2018, about 2.1 million new cases of breast cancer and 627 thousand deaths were estimated ${ }^{(2)}$. Although the incidence of breast cancer is lower in regions of medium and low income, the developing countries reveal the highest mortality rates ${ }^{(1)}$.

Breast cancer is a malignancy of the breasts that causes breast symptoms and changes, such as lumps, localized pain, nipple symptoms or skin alterations ${ }^{(3)}$. In early breast cancer without metastasis, women undergo breast surgery and, commonly, need a form of systemic therapy ${ }^{(3)}$. Surgical treatment is done mainly through either mastectomy or breast-conserving surgery. Currently, studies ${ }^{(4-6)}$ have demonstrated equivalence in overall survival between both surgical techniques. Thus, in the absence of medical contraindications, the decision for which surgical therapy should be used becomes a personal matter.

In a mastectomy, women experience entire breast removal, thereby resulting in a permanent change in their appearance ${ }^{(7)}$. In this regard, besides the complications arising from the illness, breast cancer and its treatment have repercussions caused by the total or partial mutilation of the breast, often resulting in problems associated with body image (BI), self-acceptance, sexuality and quality of life $(\mathrm{QoL})^{(8)}$.

$\mathrm{BI}$ is a psychological construct about perceptions, emotions and attitudes that individuals hold towards their own body ${ }^{(9)}$. In breast cancer, treatment can affect $\mathrm{BI}$, as the loss of an organ full of symbols and identity brings to the survivors dissatisfaction with appearance, perceived loss of femininity and body integrity, reluctance to look at one's self naked, as well as feeling less sexually attractive ${ }^{(10)}$. Furthermore, the perception of $\mathrm{BI}$ is a key determinant of $\mathrm{QoL}^{(7)}$.

Sexuality is an essential aspect of the life of cancer patients. Nonetheless, an impaired sexuality is highly prevalent among those who experience cancer, especially breast cancer, which emphasizes suffering and worry about the disease, also damaging $\mathrm{QoL}^{(11)}$. Certainly, the loss of the whole breast, a secondary sex organ, causes a variety of psychological changes and sexual complaints, including loss of attractiveness and decreased sexual interest, excitement and orgasms ${ }^{(12)}$.

$\mathrm{BI}$ and sexuality are important factors in the QoL of women with breast cancer. Besides, it is widely accepted that mastectomy represents a considerable disruption in these aspects. Therefore, studying post-surgical sexuality and BI proves to be 
relevant to health care planning, for both health professionals and public health policies. Moreover, in therapeutic planning, patients should be informed not only about the impact of surgery on cancer remission but also on health-related QoL. This includes information about possible changes in BI and sexual well-being. Although data regarding the QoL of patients with breast cancer are found in the literature, there is a lack of reviews with a specific focus on BI and sexuality after mastectomy.

Thus, this systematic review aims to comprehend how mastectomy impacts BI and sexuality of women who have undergone breast cancer treatment, as well as to provide a general understanding of these patients' QoL.

\section{Materials and Methods}

This review followed the Preferred Reporting Items for Systematic Reviews and Meta-analyses (PRISMA) guidelines.

\section{Search strategies and eligibility criteria}

A bibliographic search was conducted on June 2, 2020, in the following databases: Lilacs (Literatura Latinoamericana y del Caribe en Ciencias de la Salud), Scielo (Scientific Electronic Library Online), Pubmed and Scopus. The search terms used were "Mastectomy AND (sexuality OR "body image")". Filters were also applied regarding language and publication date, and only texts in Portuguese, Spanish or English, published between 2010 and 2020, were selected.

Accordingly, 1221 articles were identified through this search. Duplicates between databases were excluded and the remaining texts underwent an evaluation of their title, abstract and keywords. This analysis was performed by peers, and the divergences were solved by a third reviewer. For this purpose, the criteria described in Table 1 were used. After this process, publications that did not meet the inclusion criteria were excluded and the remaining articles were retrieved for a full-text assessment.

Then, the selected texts were fully read. It is noteworthy that this assessment was also carried out by peers, with disagreements resolved by a third reviewer. Articles that did not fit the selection criteria (depicted in Table 1) or did not have the full text available were excluded. At the end of this process, 62 articles were selected for inclusion and analysis in this review.

Table 1. Inclusion and exclusion criteria

\begin{tabular}{cc}
\hline Inclusion criteria & Exclusion criteria (EC) \\
Articles written in Portuguese, English or & $\begin{array}{c}\text { Articles with an approach out of the } \\
\text { Spanish; }\end{array}$ \\
context of the investigated subject; \\
Articles published between 2010 and & Articles from literature review studies; \\
$2020 ;$ & $\begin{array}{c}\text { Articles in the form of dissertation, thesis, } \\
\text { book chapter, book, manual, editorial, } \\
\text { review, comment, criticism, report, letter, } \\
\text { note, conference paper and manuscript; }\end{array}$ \\
\hline
\end{tabular}


Studies that addressed mastectomy as a treatment for breast cancer and analyzed its impact on women's body image and / or sexuality;

Articles that addressed breast cancer exclusively in women;

Articles that addressed these issues from the perspective of mastectomized women and not according to the perception of other people towards them.
Articles that addressed the body image of women who underwent prophylactic mastectomy, whether they did not have breast cancer or underwent contralateral breast removal;

Studies that included only women who had breast reconstruction surgery or only women who had breast-conserving surgery;

Studies performed with women who had breast cancer recurrence or metastasis;

Articles that addressed other people's perceptions of mastectomized women;

Studies that did not use validated scales to measure results.

\section{Data extraction and synthesis}

Data from the included publications were extracted. Then, a table was created and the following variables were established to be collected: First author, year and country; Sample group; Age of participants (mean and range); Surgical procedure(s); Questionnaire(s) applied and Results (Table 2). A pilot test was carried out with 5 randomly chosen articles and, later on, all the included texts were tabulated. This work was conducted by two independent reviewers, with divergences being evaluated by a third reviewer. It is important to highlight that, in the "Results" column, the main findings of the studies related to the topic addressed in this review were summarized, but the results not associated with the present analysis were not described, such as data related to arm symptoms and to the development of depression after mastectomy. Finally, the extracted data were assessed according to the objective of this work.

\section{Results}

1221 articles were identified (36 at Lilacs, 18 at Scielo, 556 at Pubmed and 611 at Scopus), of which 389 were excluded due to duplication between databases, thus remaining 832 texts for analysis. Then, in the first evaluation stage, based on reading the title, abstract and keywords, 709 papers that did not meet the inclusion criteria were excluded. The remaining 123 publications were fully examined. Of these, 61 were excluded, 55 for not meeting the selection criteria (Table 1) and 6 for not having the full text available. At the end of this process, 62 articles were selected for data extraction and inclusion in this review (Figure 1). 
Figure 1. Flow diagram of study selection according to PRISMA guidelines

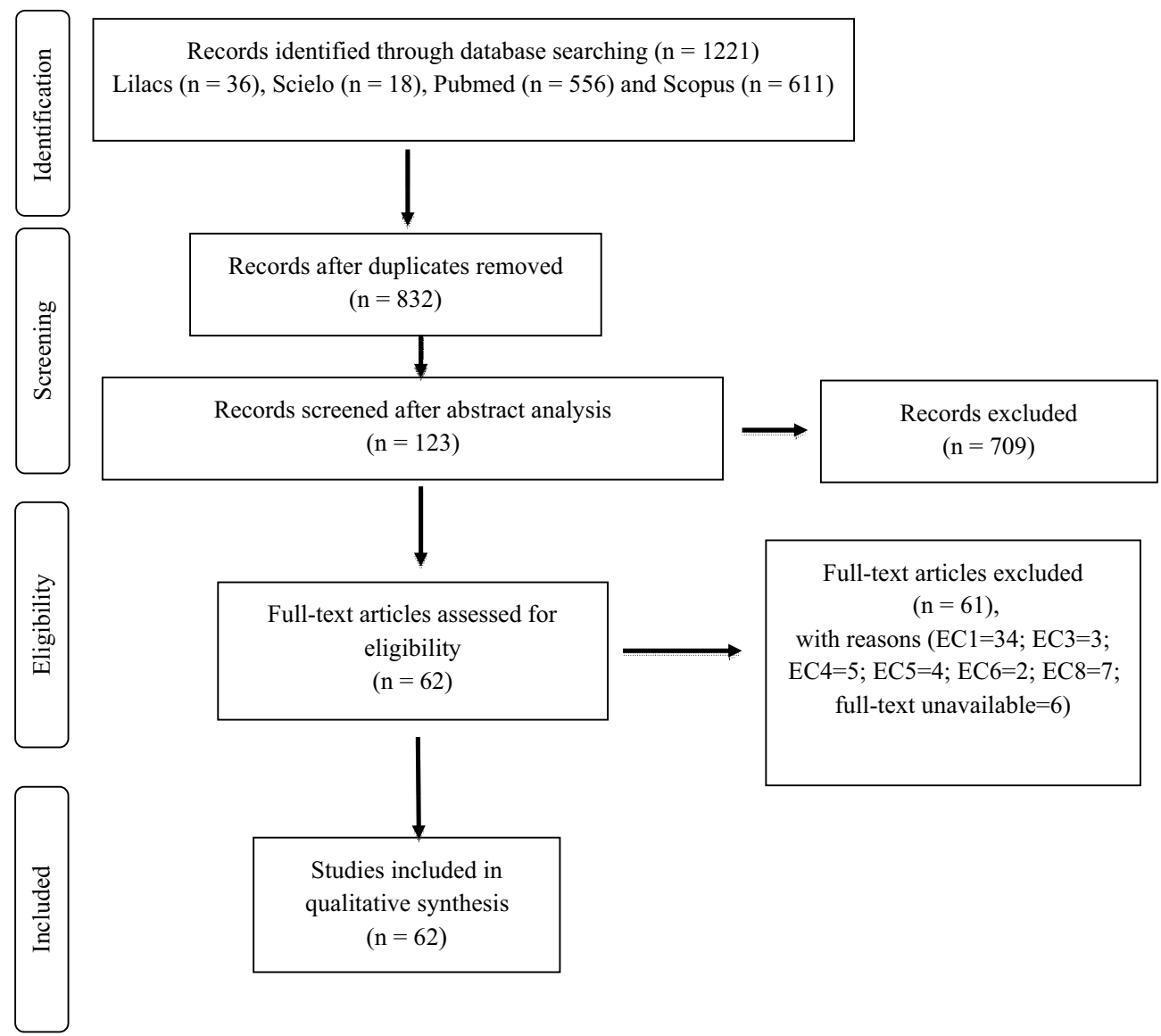

Mastectomy was seen in the given studies as a factor that affects several areas of the life of women with breast cancer. In this review, an analysis was carried out focusing on its repercussions on the BI, sexual functioning (SF) and QoL of these patients.

The included articles approach the impact of mastectomy on QoL, SF and BI of women with breast cancer, also bringing a comparison with the impact of other surgical treatments, such as breast-conserving surgery, lumpectomy and breast reconstruction. The total number of participants in the analyzed studies was 10877 . The minimum and maximum age of the patients were 18 and 94 years, respectively. The mean age of participants among the studies that brought that information was 51.4 years. 61 different questionnaires were used in the studies, among which the most frequently used were: (EORTC QLQ-BR23) in 19 studies (30.6\%), (EORTC QLQ-C30) in 18 studies (29.0\%), (FSFI) in 14 studies (22.6\%) and (BIS) in 12 studies $(19.3 \%)$. 


\section{Body Image}

BI was addressed in $64.5 \%$ (40) of the analyzed articles. Mastectomy was a major impact factor in the BI of women with breast cancer in $46.7 \%$ (29) of the studies, both in short and long term. Furthermore, 24.2\% (15) of the texts showed that the impact of mastectomy was worse than that of other surgical treatments (breast-conserving surgery, lumpectomy and breast reconstruction). In addition, the damage was greater in mastectomized patients when compared with the control group in $1.6 \%$ (1) of the articles.

Breast-conserving surgery was the second type of surgical treatment for breast cancer that had the most negative repercussions in BI. Nevertheless, in 3.2\% (2) of the texts, the losses caused by mastectomy and breast-conserving surgery in BI were comparable.

Breast reconstruction is an effective way to improve the BI of women after surgical treatment for breast cancer, which was seen in $4.8 \%$ (3) of the articles. However, 2 other studies reported that delayed reconstruction had a negative effect on BI. Moreover, $1.6 \%$ (1) of the texts concluded that breast cancer patients who did not receive any surgical treatment showed a more impaired BI than those who did.

Finally, 1.6\% (1) of the articles associated better BI with an investment in selfcompassion and appearance. Furthermore, another article (1.6\%) related worse BI with post-treatment weight gain. Also, 1 article revealed that women who underwent nipple-sparing mastectomy with immediate reconstruction had moderately low levels of BI disorders.

\section{Sexuality}

Sexuality is directly affected by the surgical treatment of breast cancer. Thus, an association between breast surgery and impaired SF or sexual dysfunction (SD) was shown in $56.4 \%$ (35) of the assessed articles. Mastectomy harmed SF or caused greater SD in $4.8 \%$ (3) of the studies. Several texts brought a comparison between the types of treatment regarding their impact on women's sexuality: 8 articles showed that mastectomy had a worse impact on SF or caused greater SD when compared with breast-conserving surgery. Conversely, 2 other articles concluded that conservative surgery was worse for SF than mastectomy. Yet, another 3 studies demonstrated that both mastectomy and breast-conserving surgery similarly worsened SF or contributed to the development of SD. Moreover, 1.6\% (1) of the articles exhibited that worse SF was associated with post-treatment weight gain.

Regarding lumpectomy, 4.8\% (3) of the articles revealed better results in SF or less SD when compared with mastectomy. Furthermore, 3.2\% (2) of the studies reported that SF was more affected in mastectomized women than in the control group. Additionally, 2 texts showed that SF has a strong tendency to decline over time. Also, it was evident that breast reconstruction is a viable alternative to improve SF, given that $17.7 \%$ (11) of the articles correlated it with improvements on SF or lower SD. Moreover, one study noted that SF is directly related to the age of the patients.

Remarkably, 1.6\% (1) of the articles reported the existence of a positive correlation between SF and BI, and another study showed that partners' support also correlates with SF scores. Moreover, in 6.4\% (4) of the texts, circumstances such as absence of 
partner, high level of education, absence of breast reconstruction, advanced age and marital status were associated with greater SD. Yet, another article (1.6\%) showed that lower levels of education and having an older partner were contributing factors for worse SF. Furthermore, 1 article (1.6\%) associated younger age, being married and elementary education level with worse SF. However, $1.6 \%$ (1) of the studies showed that SF improved as the education and income of women with mastectomy increased.

\section{Quality of Life}

QoL is another aspect that is greatly impaired by procedures that modify the patient's body shape, such as mastectomy, and was addressed in $32.2 \%$ (20) of the selected articles. 24.2\% (15) of the studies mentioned an association between QoL and mastectomy: 6.4\% (4) simply showed that the procedure negatively affected QoL; $9.7 \%$ (6) reported that breast-conserving surgery would be better than mastectomy in terms of QoL, and 1.6\% (1) pointed out that lumpectomy had less significant impacts on QoL than mastectomy.

Moreover, $3.2 \%$ (2) of the articles concluded that the QoL of mastectomized women improved over time. Furthermore, 2 studies showed that, concerning QoL, breast-conserving surgery was worse than mastectomy, with age influencing in these cases: younger women have a positive impact with mastectomy, but older women do not. Also, 1.6\% (1) of the studies reported that younger women had their QoL more affected by surgery when compared with older women. Nevertheless, $1.6 \%$ (1) of the articles showed some similarity in the perception of QoL between patients who underwent mastectomy and those who underwent breast-conserving surgery. Also, $4.8 \%$ (3) of the texts reported breast reconstruction as an effective way to mitigate the damage of surgery in patients' QoL. Finally, in 1.6\% (1) of the articles, there was a positive correlation between BI and QoL. 


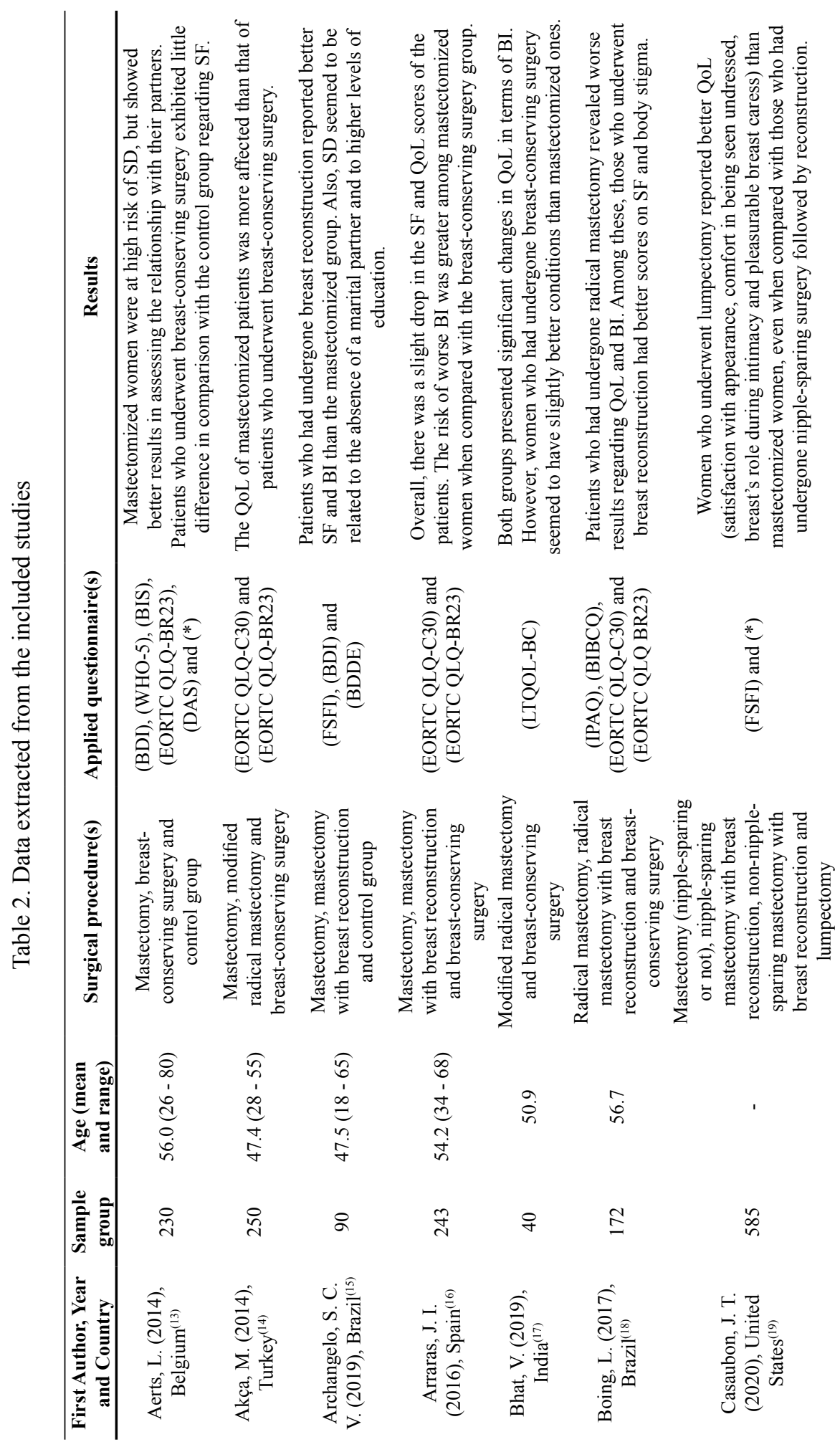




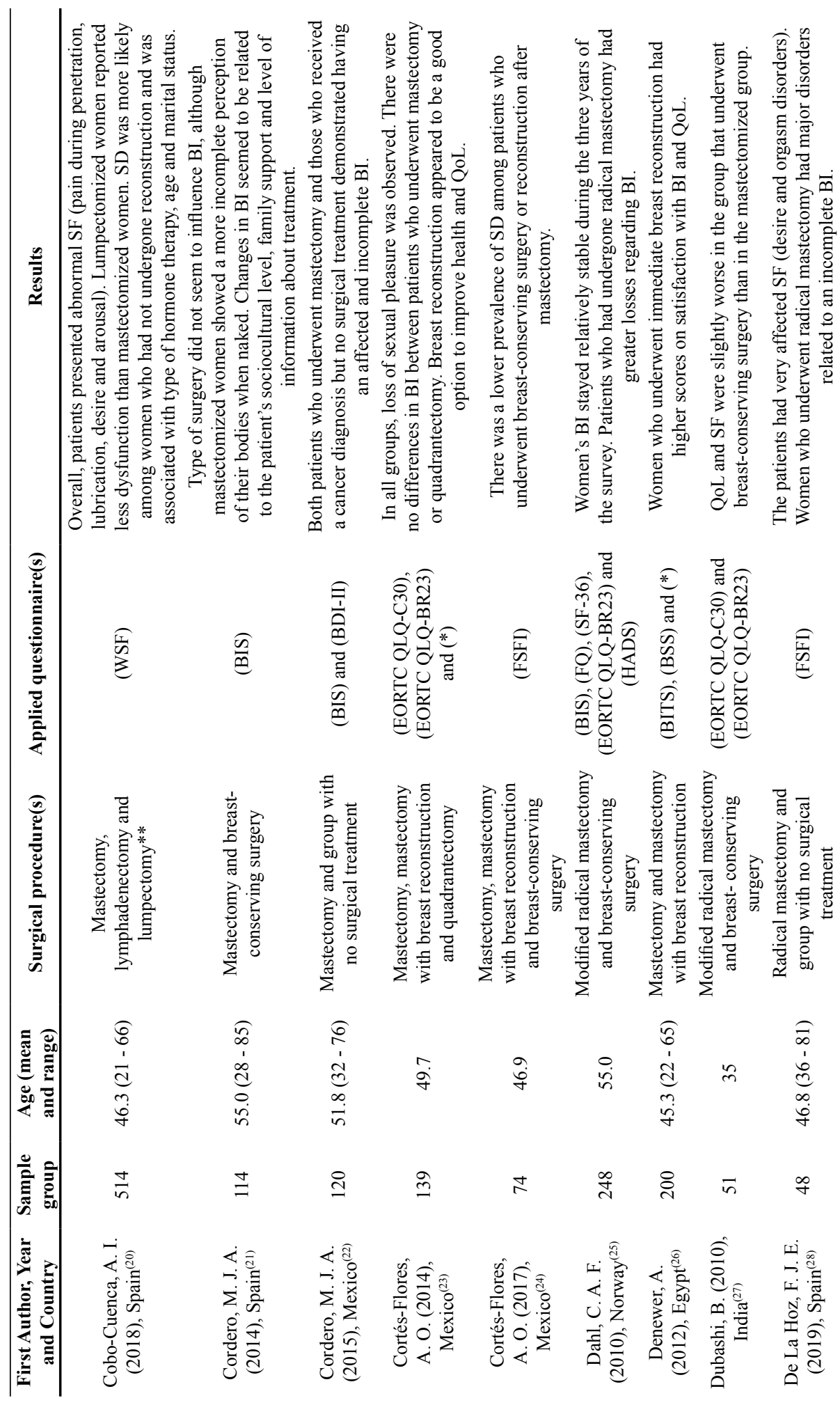




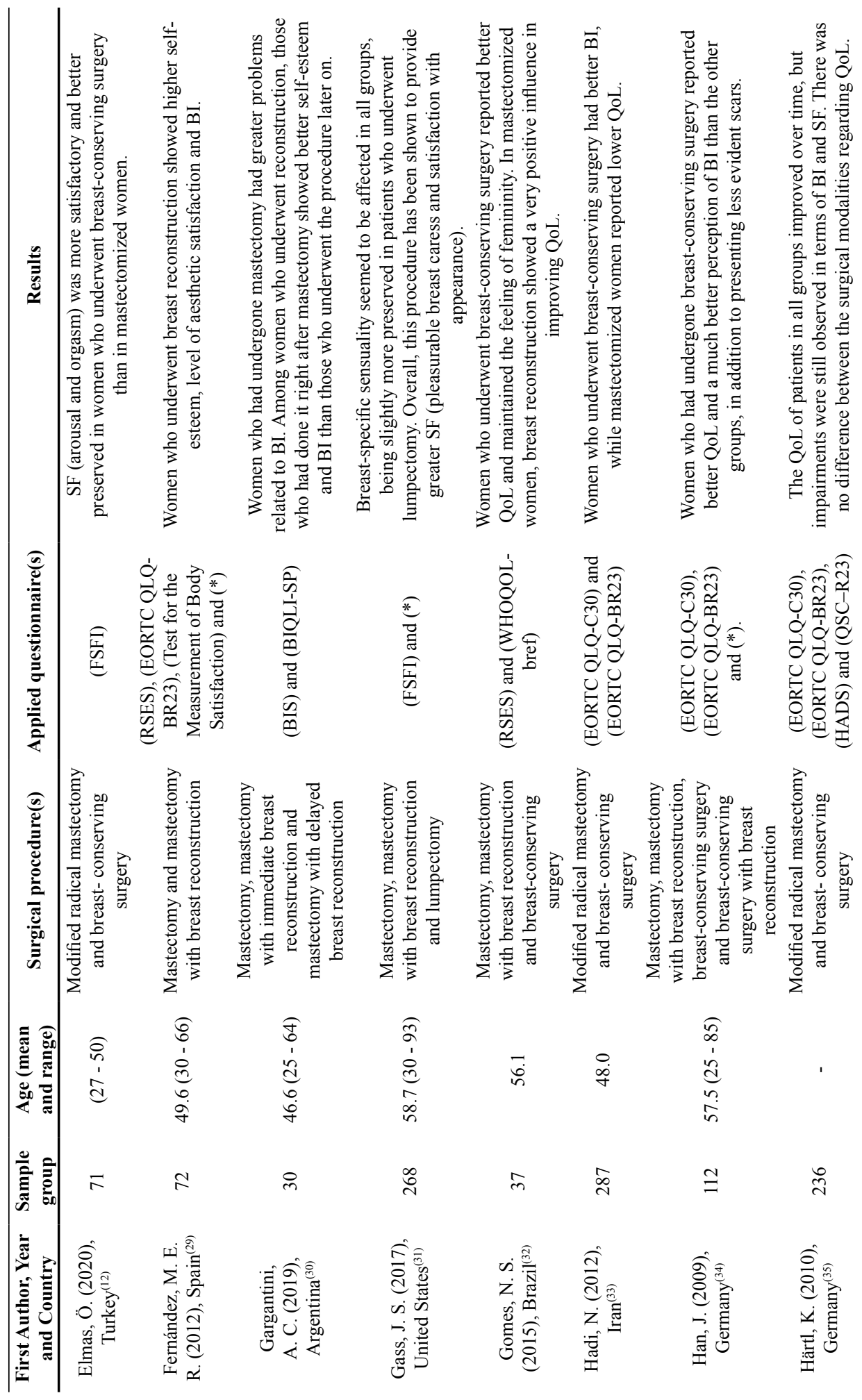




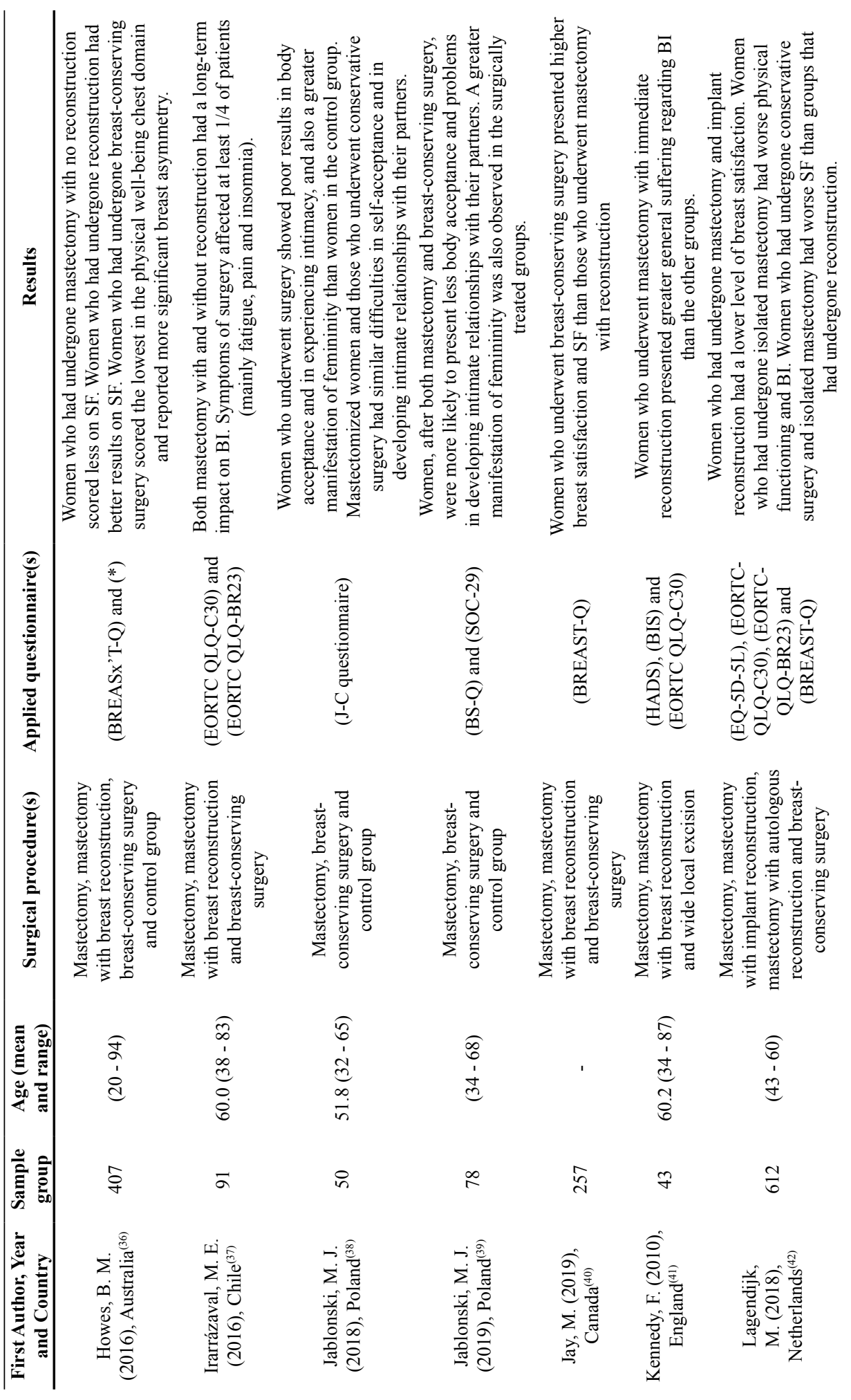




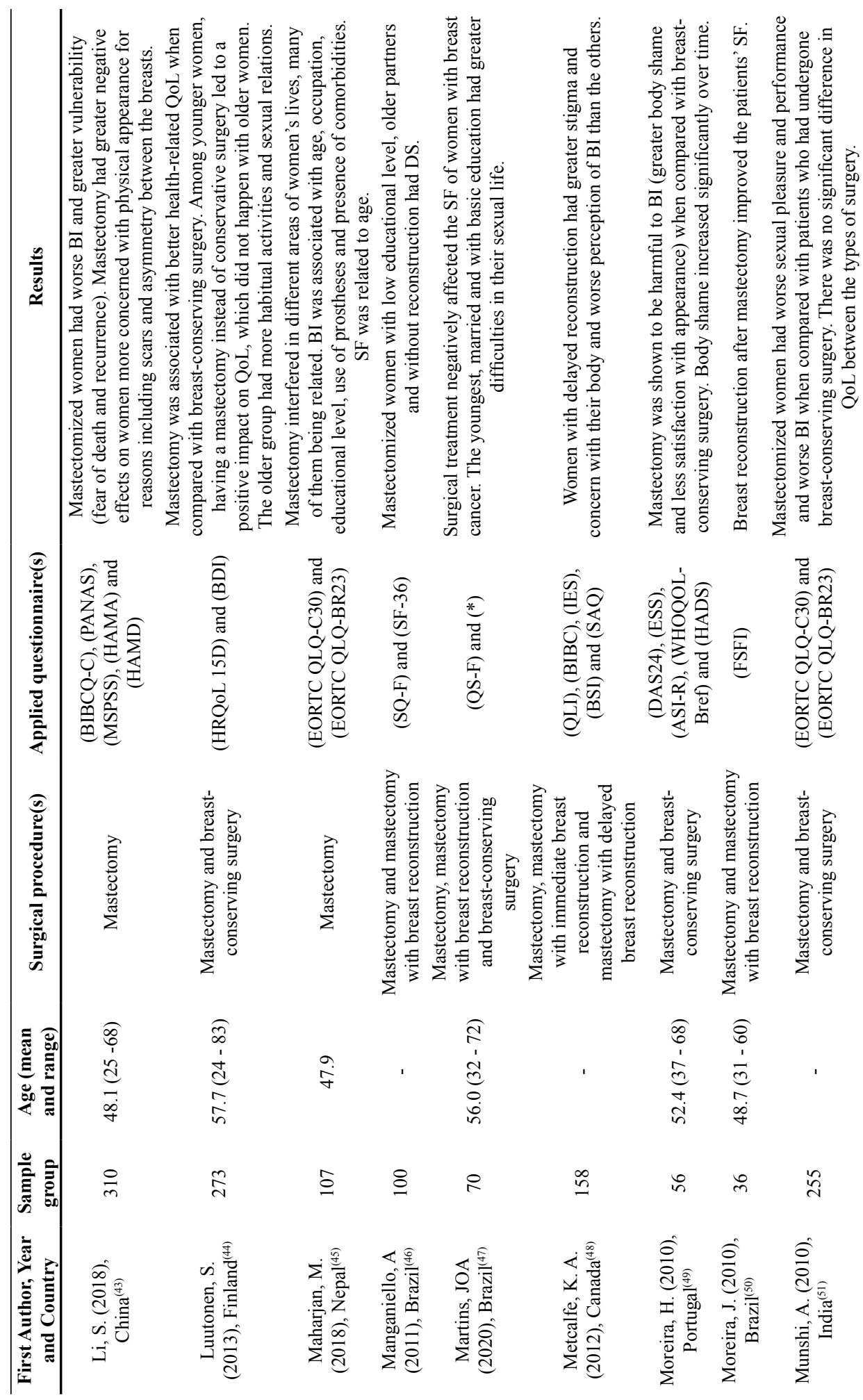




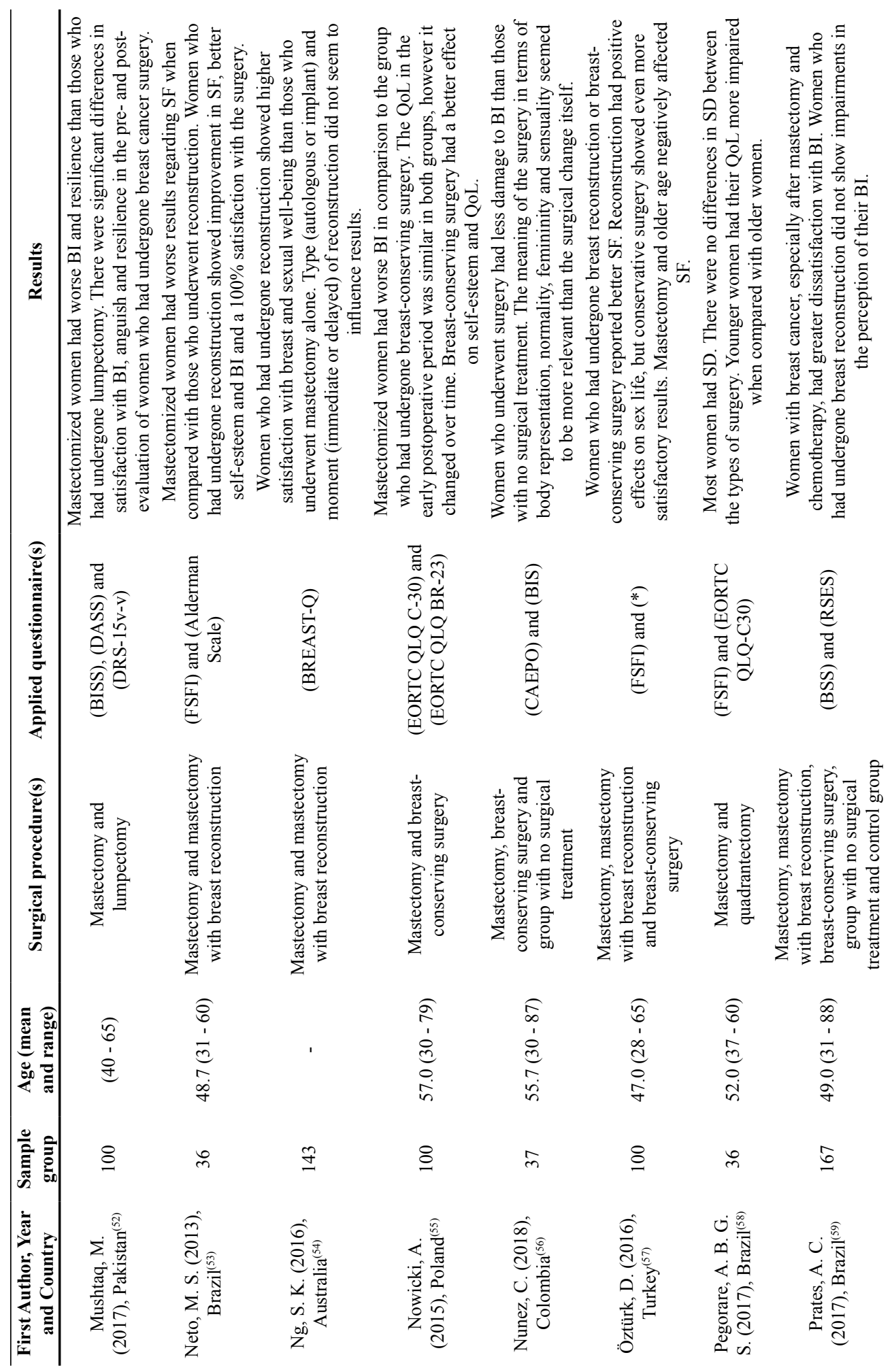




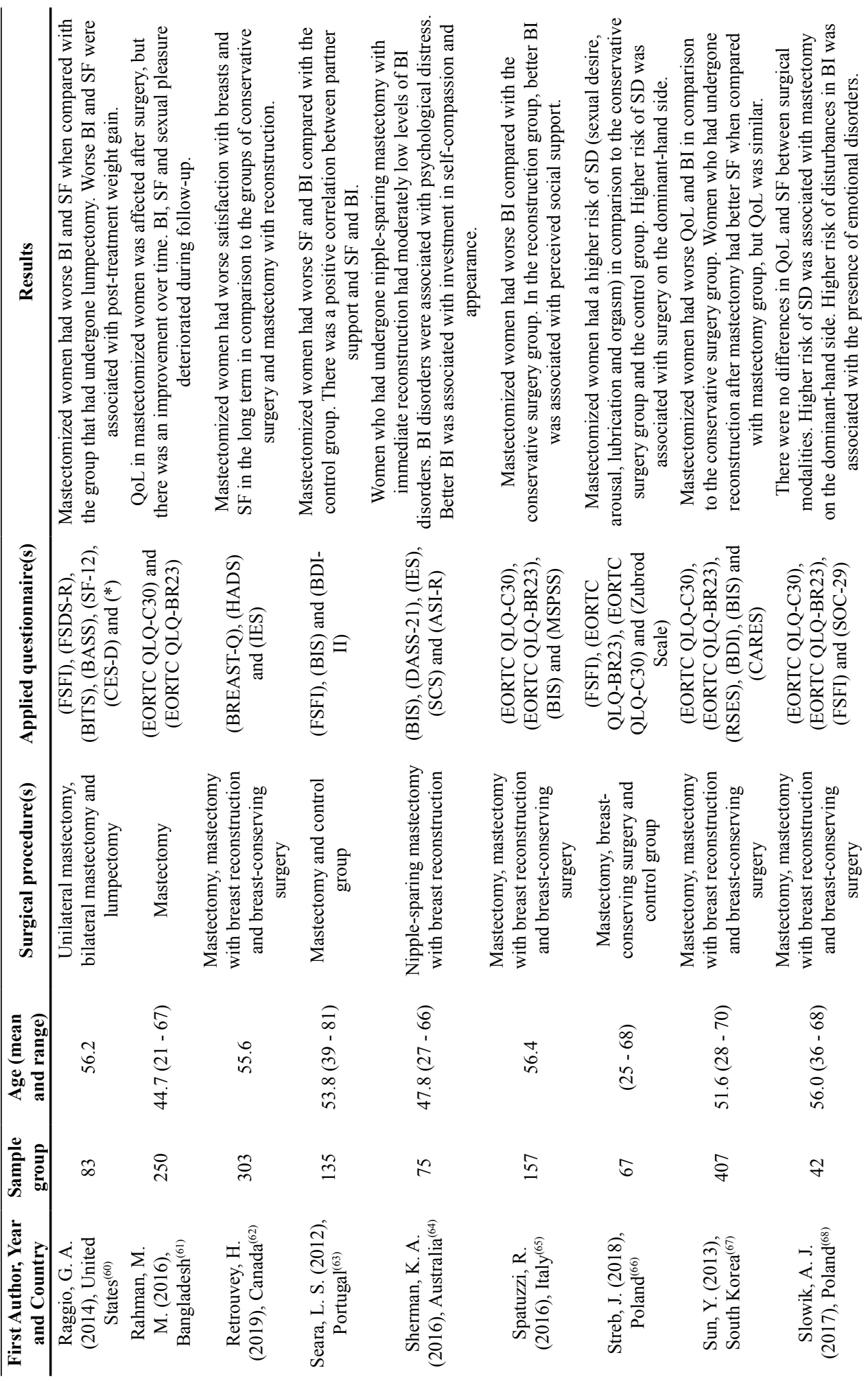




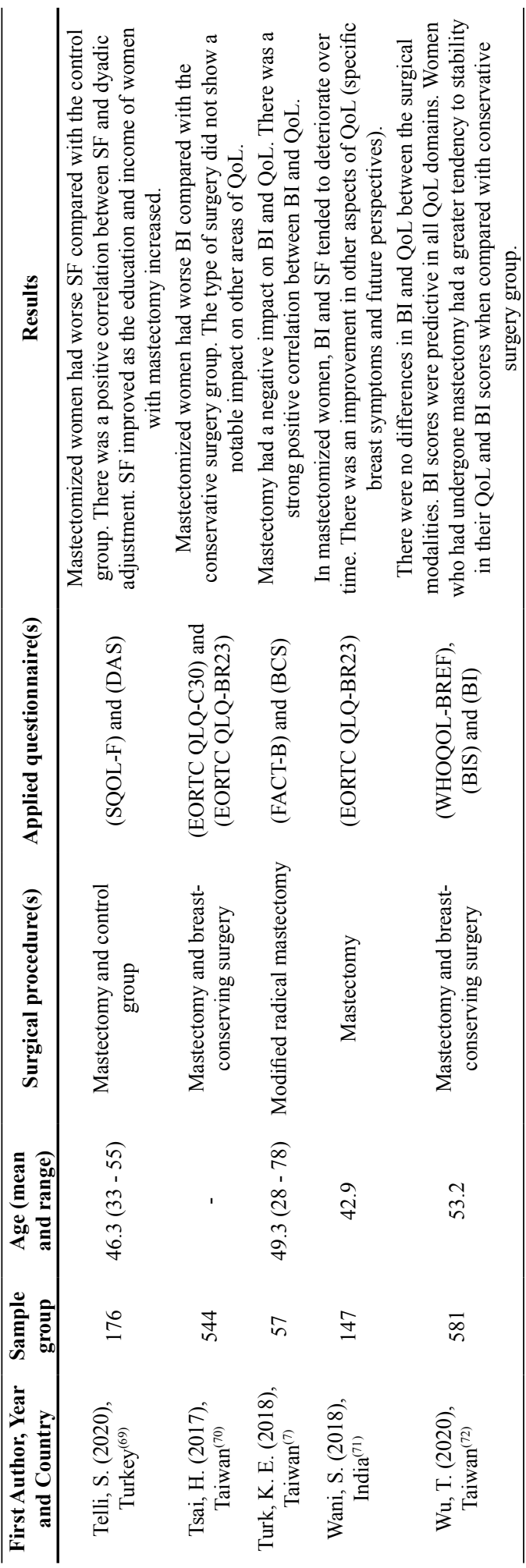

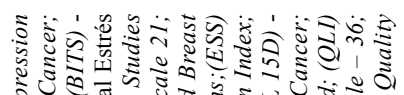

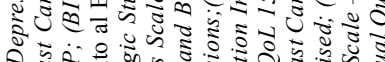

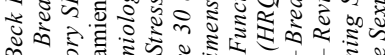

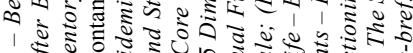
₹

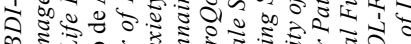

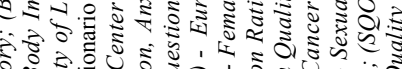

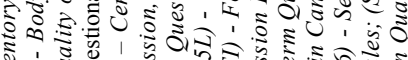
引

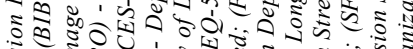

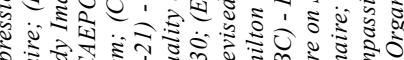

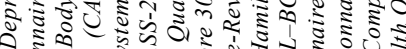
व.

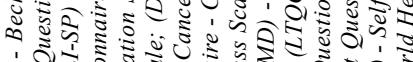

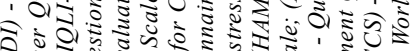
च จ 落

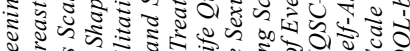

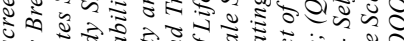

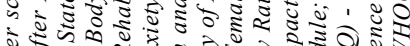
उ कू

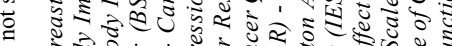

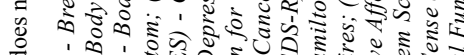

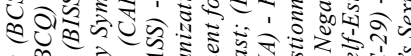
फ

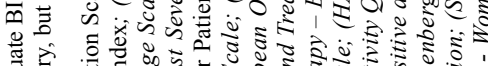

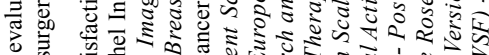

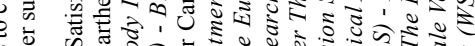

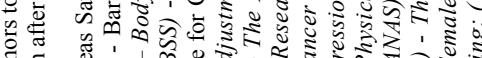
冚.

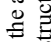
고

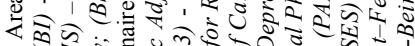

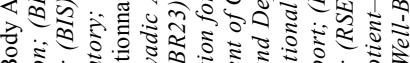

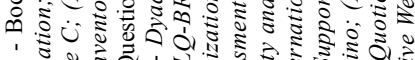

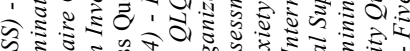

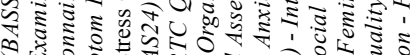

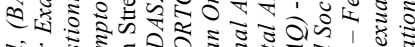

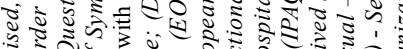
.

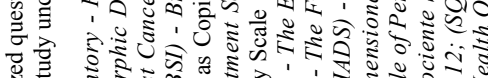

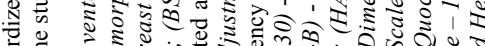

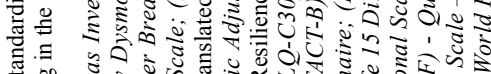
का

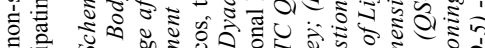
織

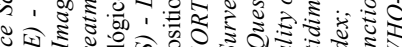

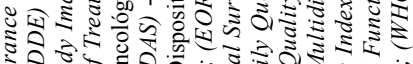

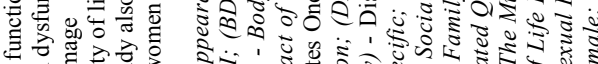

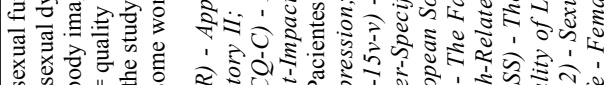

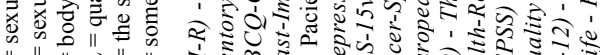

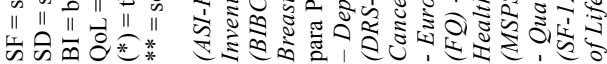




\section{Discussion}

\section{Body Image}

BI is not restricted to the perception of the physical appearance of the body itself, once it also involves psychological, social and cultural facets. Thus, removal of the breast, an organ full of meanings and social representations, can cause serious changes in women's body perception ${ }^{(73)}$.

Overall, the results of this review showed that mastectomy is a major impact factor on the BI of women with breast cancer, both in short and long term. Indeed, when compared with other forms of surgical treatment (such as breast-conserving surgery), radical breast removal revealed worse levels of satisfaction with BI. These results reinforce the findings of other reviews, which also argue that mastectomy has a greater impact on $\mathrm{BI}$ than other surgical modalities ${ }^{(74,75)}$. According to Aureliano ${ }^{(76)}$, the breast has a strong symbolic meaning, for being part of the social conception of womanhood. Hence, mastectomy represents a fragmentation of the female body, in which the symbol of women's femininity and sexuality becomes disposable. In this regard, even after cure, the breast removal leaves a permanent mark on the perception of their own body ${ }^{(76)}$.

Furthermore, breast reconstruction proved to be an important way of restoring a complete BI in some articles. This can be justified by the fact that this surgery seeks to rebuild the breasts' symbolic representation, offering women a BI closer to what is socially established as "normal" and feminine ${ }^{(7)}$. This result is consistent with the findings of the review performed by Santos and Vieira ${ }^{(74)}$, that understood reconstruction as a valuable tool for improving BI.

Given the symbolic importance of breast, as well as the potential positive effects of reconstruction, yet another result of this review can be explained: the low levels of BI disorders among patients who underwent nipple-sparing mastectomy with immediate breast reconstruction. After all, the nipple is extremely important for the full function and recognition of the breast and its preservation can reduce the feeling of mutilation, thus allowing a result closer to the original breast after reconstruction ${ }^{(77)}$.

Importantly, a minority of studies have shown evidence that delayed reconstruction can impair BI. As reported by Aureliano ${ }^{(76)}$, reconstruction, despite its opposite goal, can generate the feeling of a transformed, reconstructed body for many women. Therefore, it could be understood as another mutilation, a useless modification ${ }^{(76)}$. This would explain why, when performed late in the process of readaptation and reformulation of one's body perception, reconstruction negatively affected the BI of certain women included in this review. Such results add to what is stated in the research conducted by Almeida et al. ${ }^{(75)}$, which concluded that there is no consensus about the impact of reconstruction, whether immediate or delayed, on the BI of women with cancer.

The studies also depicted other factors that influence levels of satisfaction with $\mathrm{BI}$, besides the type of surgical procedure. Investment in self-compassion and appearance was associated with better BI, whereas weight gain after treatment with worse BI. According to Oliveira et al. ${ }^{(73)}$, women undergo, after mastectomy, a complex process of accepting their "new body", which suffers great external influence and depends largely on social approval. Hence, the importance of investing in self-compassion, once it allows women to value BI without depending on external validation. Furthermore, the weight stigma and the modern "beauty standards" can 
make the fat body seem inadequate, not acceptable ${ }^{(78)}$. This factor can make people feel undesirable and seriously affect BI, but this is even further enhanced by the loss of the breast. Therefore, it is natural to understand that the body acceptance of mastectomized women who gain weight after treatment is more severely affected.

\section{Sexuality}

Sexuality involves the integration of different dimensions, including the individual, the cultural, the physical, the affective and the social. As breast removal interferes in many of them, it also manifests itself as an amputation of sexuality, desire, feeling of femininity and attractiveness ${ }^{(79)}$.

Overall, mastectomy has proved to be a major impact factor in the SF of women with breast cancer, when compared not only to the control group, but also to the surgical modalities of breast-conserving surgery and lumpectomy. According to Vaziri and Lotfi-Kashani ${ }^{(80)}$, the ability to achieve a healthy SF involves psychological and physical factors that affect the sexual response cycle, for example, desire, arousal and orgasm. Furthermore, breasts carry a strong symbolic content as an attribute of female beauty, attractiveness and sexual identity of women ${ }^{(73)}$. Thereby, total breast removal affects specific aspects of SF and intimacy and manifests as a mutilation of the female body, causing changes in the understanding of one's sexual self.

Moreover, breast reconstruction was correlated with improvements in SF or associated with a lower risk of SD, thus representing a promising alternative to restore and improve SF. As reported by Hart et al. ${ }^{(81)}$, this is explained by the fact that the reconstruction gives women back the feeling of normality and the symbolism that the organ carries, acting in the maintenance of femininity, the feeling of sexual attractiveness and confidence during intimate relationships. These findings are consistent with the review conducted by Gilbert et al. ${ }^{82}$, wherein mastectomy compared with breast-conserving surgery or reconstruction was shown to result in greater feelings of body shame, reluctance to look at one's body, a negative BI, and a lower perceived sexual attractiveness. In turn, Santos et al. ${ }^{(83)}$ stated that there was no consensus in the literature regarding which surgical modality has the least adverse consequences for SF of women with breast cancer.

Factors including post-treatment weight gain, time elapsed after surgery, age, education level, marital status, presence or absence of a partner, partner support, age of the partner, BI and income were either positively or negatively correlated with SF. Conforming to Male et al. ${ }^{(84)}$, post-treatment weight gain is associated with feelings of distress and worse BI, which explains a more impaired SF in these women. The SF deterioration over time observed in two articles was also noticed in the review conducted by Boswell and Dizon ${ }^{(85)}$, which argued that, although some problems improved over time, SF was not one of them.

Despite divergences in the included studies on the impact of age on SF, Chang et al. ${ }^{(86)}$ described that older women give less importance to the breasts and the deterioration of intimate relationships, and also worry less about their reproductive functions. Moreover, partner support was shown to be associated with better SF, however, marital status and the presence or absence of a partner were controversial. About this subject, Chang et al. ${ }^{(86)}$ also stated that partners are valuable sources of support for women with breast cancer, but having a partner that does not provide support is harmful. 


\section{Quality of Life}

The development of a woman's QoL is related to a variety of factors, including her body perception. Considering the role of the breasts in sensuality and in feminine aesthetics, their major influence in this process becomes evident. Hence, since mastectomy promotes breast removal, the procedure can cause great impacts on patients' QoL ${ }^{(73)}$.

In general, the results of the present study referred that mastectomy negatively influenced the QoL of patients with breast cancer. After all, partial or total breast removal can cause complications to sexual health, to practice of physical and domestic activities and to family life, once this organ is full of symbolism and female identity, directly affecting women's self-esteem ${ }^{(87)}$. There was also evidence that, over time, women tend to have progressive improvements in QoL. Given that there is a disruption of the female body's integrity with mastectomy, time is necessary so that they can accept this change and rebuild their $\mathrm{BI}^{(76)}$.

When compared to the modalities of conservative surgery, mastectomy showed greater impact on women's QoL in most studies. The advantage of breast-conserving surgery can be explained by its association with a more positive $\mathrm{BI}^{(88)}$, since it promotes less body modification. This reinforces the data presented in the systematic review conducted by Simeão et al. ${ }^{(87)}$, which concluded that mastectomized women without reconstruction had worse QoL scores.

Moreover, in some studies, breast reconstruction has proved to be an important way of mitigating the damage caused by mastectomy on QoL. Previous research associated $\mathrm{BI}$ to $\mathrm{QoL}$, indicating that these factors have a strong positive correlation. The systematic review by Cordova et al. ${ }^{(89)}$ also showed positive results for patients who underwent breast reconstruction, justified by the aesthetic concern with their bodies. After all, in a context of overvaluation of aesthetic standards and body stereotypes, women who undergo total breast removal often feel frustrated and may develop subsequent psychosocial problems.

Another factor associated with QoL levels was the age of the participants, however, there were controversies regarding the influence exerted by it. Younger age was sometimes related to a more positive impact of mastectomy when compared with conservative surgery, which can be explained by the fear of cancer recurrence and the concern of younger women to heal themselves to care for their children and family $^{(76)}$. Nonetheless, in other studies, younger age was associated with a greater impact on QoL after surgery, which can be justified by the greater tendency of younger women to be concerned with physical appearance, femininity and sexuality ${ }^{(90)}$.

\section{Limitations}

Some limitations observed in the present study were the non-inclusion of books and the so-called "gray literature" in the search for articles and the non-use of a mechanism to assess the risk of bias in the analyzed studies.

A strength of this review was the analysis of articles that used exclusively standardized questionnaires. Notwithstanding that, many different and sometimes generic questionnaires were applied, which complicated the assessment and standardization of results. 
Finally, most of the articles included in this literature review evaluated aspects related to BI, SF and QoL in only one moment of patients' lives. Therefore, their evolution over time and in long term was only considered in a few studies

\section{Conclusion}

Published data regarding BI, sexuality and QoL of mastectomized women were analyzed in this review. The majority of studies pointed out evidence that mastectomy is the surgical modality that causes the greatest impact on BI and sexuality, including impairment on QoL. In addition, breast reconstruction proved to be a procedure capable of improving patients' BI, SF and QoL, especially if performed immediately.

There are also factors (investment in self-compassion, weight gain after surgery, age, marital status, among others) that can either positively or negatively influence the BI, SF and QoL of women after mastectomy. Another relevant variable was time after surgery: there was evidence of progressive improvement in QoL and acceptance of BI over the years. Adversely, there may be deterioration in SF.

Concerning the practical implications of this review, physicians should, whenever possible, take into account throughout the therapeutic choice the disorders that mastectomy may cause and provide options to the patients. Furthermore, women must be informed about the impacts of mastectomy on BI, SF and QoL in order to have greater autonomy in the process of choosing a therapeutic method.

Finally, only a small number of studies explored the evolution of BI, SF and QoL over time. Likewise, there was a lack of specific data on the interference of factors, such as age and marital status, in BI, SF and QoL, as they still remain controversial in the present literature. Therefore, it is pivotal that new studies develop these questions. After all, they are relevant to the professional who seeks to better guide patients on how the types of surgery impact the QoL of women with breast cancer.

\section{References}

1. Winters S, Martin C, Murphy D, Shokar NK. Breast Cancer Epidemiology, Prevention, and Screening. Prog Mol Biol Transl Sci 2017;15:1-32. doi:10.1016/bs.pmbts.2017.07.002

2. Ferlay J, Colombet M, Soerjomataram I, Mathers C, Parkin DM, Piñeros M, et al. Estimating the global cancer incidence and mortality in 2018: GLOBOCAN sources and methods. Int J Cancer 2019;144:1941-53. doi:10.1002/ijc.31937

3. Harbeck N, Penault-Llorca F, Cortes J, Gnant M, Houssami N, Poortmans P, et al. Breast cancer. Nat Rev Dis Prim 2019;5:66. doi:10.1038/s41572-019-0111-2

4. Vila J, Gandini S, Gentilini O. Overall survival according to type of surgery in young ( $\leq 40$ years) early breast cancer patients: A systematic meta-analysis comparing breastconserving surgery versus mastectomy. Breast. 2015;24:175-81. doi:10.1016/j. breast.2015.02.002

5. McLaughlin SA. Surgical management of the breast: breast conservation therapy and mastectomy. Surg Clin North Am 2013;93:411-28. doi:10.1016/j.suc.2012.12.006

6. Sinnadurai S, Kwong A, Hartman M, Tan EY, Bhoo-Pathy NT, Dahlui M, et al. Breastconserving surgery versus mastectomy in young women with breast cancer in Asian settings. BJS Open 2018;3:48-55. doi:10.1002/bjs5.50111 
7. Türk KE, Yilmaz M. The effect on quality of life and body image of mastectomy among breast cancer survivors. Eur J Breast Heal 2018;14:205-10. doi:10.5152/ejbh.2018.3875

8. Kołodziejczyk A, Pawłowski T. Negative body image in breast cancer patients. Adv Clin Exp Med 2019;28:1137-42. doi:10.17219/acem/103626

9. Muzzatti B, Annunziata MA. Body image assessment in oncology: an update review. Support Care Cancer 2017; 25:1019-29. doi:10.1007/s00520-016-3538-y

10. Koçan S, Gürsoy A. Body Image of Women with Breast Cancer After Mastectomy: A Qualitative Research. J Breast Heal. 2016;12:145-50. doi:10.5152/tjbh.2016.2913

11. Lindau ST, Abramsohn EM, Matthews AC. A manifesto on the preservation of sexual function in women and girls with cancer. Am J Obs Gynecol 2015;213:166-74. doi:10.1016/j.ajog.2015.03.039

12. Elmas Ö, Çakmak GK, Bakkal BH. A comparison between breast-conserving surgery and modified radical mastectomy concerning the female sexual function in breast cancer patients under 50 years of age. Turk J Oncol 2020;35:26-30. doi:10.5505/tjo.2019.2135

13. Aerts L, Christiaens MR, Enzlin P, Neven P, Amant F. Sexual functioning in women after mastectomy versus breast conserving therapy for early-stage breast cancer: A prospective controlled study. Breast 2014;23:629-36. doi: 10.1016/j.breast.2014.06.012

14. Akça M, Ata A, Nayır E, Erdoğdu S, Arıcan A. Impact of surgery type on quality of life in breast cancer patients. J Breast Heal 2014;10:222-8. doi: 10.5152/tjbh.2014.1919

15. Archangelo SC V, Neto MS, Veiga DF, Garcia EB, Ferreira LM. Sexuality, depression and body image after breast reconstruction. Clin (Sao Paulo) 2019;74. doi: 10.6061/ clinics/2019/e883

16. Arraras JI, Illarramendi JJ, De La Cruz S, Asin G, Manterola A, Ibanez B, et al. Quality of life in long-Term premenopausal early-stage breast cancer survivors from Spain. Effects of surgery and time since surgery. J BUON 2016;21:1090-8.

17. Bhat V, Roshini AP, Ramesh R. Does Quality of Life Among Modified Radical Mastectomy and Breast Conservation Surgery Patients Differ? A 5-Year Comparative Study. Indian J Surg Oncol 2019;10:643-8. doi: 10.1007/s13193-019-00962-1

18. Boing L, De Araujo CCR, Pereira GS, Moratelli J, Benneti M, Borgatto AF, et al. Sitting time, body image and quality of life in women after breast cancer surgery. Rev Bras Med Esporte 2017;23:366-70. doi: 10.1590/1517-869220172305170333

19. Casaubon JT, Kuehn RB, Pesek SE, Raker CA, Edmonson DA, Stuckey A, et al. BreastSpecific Sensuality and Appearance Satisfaction: Comparison of Breast-Conserving Surgery and Nipple-Sparing Mastectomy. J Am Coll Surg 2020;230:990-8. doi: 10.1016/j. jamcollsurg.2020.02.048

20. Cobo-Cuenca AI, Martín-Espinosa NM, Sampietro-Crespo A, Rodríguez-Borrego MA, Carmona-Torres JM. Sexual dysfunction in Spanish women with breast cancer. PLoS One 2018;13(8). doi: 10.1371/journal.pone.0203151

21. Cordero MJA, Sanchez MN, MurVillar N, Valverde EG, López AMS. Perception of body image after breast cancer surgery in women from the city of Granada. Cah Biol Mar 2014;56:2-6. doi: 10.7400/RENC.2014.01.1.5002

22. Cordero MJA, Villar NM, Sánchez MN, Pimentel-Ramírez ML, García-Rillo A, Valverde EG. Breast cancer and body image as a prognostic factor of depression: a case study in México City TT - Cáncer de mama e imagen corporal como factor pronóstico de depresión: un estudio de caso en ciudad de México. Nutr Hosp 2015;31:371-9. doi: 10.3305/nh.2015.31.1.7863 
23. Cortés-Flores AO, Morgan-Villela G, del Valle CJZF, Jiménez-Tornero J, Juárez-Uzeta E, Urias-Valdez DP, et al. Quality of life among women treated for breast cancer: a survey of three procedures in Mexico. Aesthetic Plast Surg 2014;38:887-95. doi: 10.1007/s00266014-0384-5

24. Cortés-Flores AO, Vargas-Meza A, Morgan-Villela G, Jiménez-Tornero J, del Valle CJZF, Solano-Genesta M, et al. Sexuality among women treated for breast cancer: a survey of three surgical procedures. Aesthetic Plast Surg 2017;41:1275-9. doi: 10.1007/s00266017-0960-6

25. Dahl CAF, Reinertsen K V, Nesvold IL, Fosså SD, Dahl AA. A study of body image in long-term breast cancer survivors. Cancer 2010;116:3549-57. doi: 10.1002/cncr.25251

26. Denewer A, Farouk O, Kotb S, Setit A, El-Khalek SA, Shetiwy M. Quality of life among Egyptian women with breast cancer after sparing mastectomy and immediate autologous breast reconstruction: A comparative study. Breast Cancer Res Treat 2012;133:537-44. doi: 10.1007/s10549-011-1792-8

27. Dubashi B, Vidhubala E, Cyriac S, Sagar TG. Quality of life among younger women with breast cancer: study from a tertiary cancer institute in south India. Indian J Cancer 2010;47:142-7. doi: 10.4103/0019-509x.63005

28. de la Hoz FE, Ospina DDL. Evaluación de la función sexual en mujeres con cáncer de mama, en el Quindío TT - Evaluation of sexual function in women with breast cancer in Quindío. Rev Av salud 2019;3:8-17. doi: 10.21897/25394622.1754

29. Fernández MER, Gregorio MÁPS, Más MB, Rodríguez AM. The impact of breast reconstruction on self-esteem and body image in patients with breast cancer. Univ Psychol 2012;11:25-41. doi: 10.11144/javeriana.upsy11-1.irma

30. Gargantini AC, Casari LM. body image and body image quality of life in women with mastectomy. Comparison of women with immediate reconstruction, delayed reconstruction or without reconstruction. Psicooncologia 2019;16:43-60. doi: 10.5209/PSIC.63647

31. Gass JS, Onstad M, Pesek S, Rojas K, Fogarty S, Stuckey A, et al. Breast-specific sensuality and sexual function in cancer survivorship: does surgical modality matter? Ann Surg Oncol 2017;24:3133-40. doi: 10.1245/s10434-017-5905-4

32. Gomes NS, Soares MBO, Silva SR da. Autoestima e qualidade de vida de mulheres submetidas à cirurgia oncológica de mama TT - Self-esteem and quality of life in women undergoing breast cancer surgery Autoestima y calidad de vida de mujeres sometidas a cirugía por cáncer de mama. REME 2015;19:120-6. doi: 10.5935/1415-2762.20150030

33. Hadi N, Soltanipour S, Talei A. Impact of modified radical mastectomy on health-related quality of life in women with early stage breast cancer. Arch Iran Med 2012;15:504-7.

34. Han J, Grothuesmann D, Neises M, Hille U, Hillemanns P. Quality of life and satisfaction after breast cancer operation. Arch Gynecol Obs 2009;282:75-82. doi: 10.1007/s00404009-1302-y

35. Härtl K, Schennach R, Müller M, Engel J, Reinecker H, Sommer H, et al. Quality of life, anxiety, and oncological factors: A follow-up study of breast cancer patients. Psychosomatics 2010;51:112-23. doi: 10.1176/appi.psy.51.2.112

36. Howes BH, Watson DI, Xu C, Fosh B, Canepa M, Dean NR. Quality of life following total mastectomy with and without reconstruction versus breast-conserving surgery for breast cancer: A case-controlled cohort study. J Plast Reconstr Aesthet Surg 2016;69:1184-91. doi: 10.1016/j.bjps.2016.06.004

37. Irarrázaval ME, Kleinman P, Silva RS, González LF, Torres C, Fritis M, et al. Quality of life in chilean breast cancer survivors. Rev Med Chil 2016;144:1567-76. doi: 10.4067/ S0034-98872016001200008 
38. Jabłoński MJ, Streb J, Mirucka B, Słowik AJ, Jach R. The relationship between surgical treatment (mastectomy vs. breast conserving treatment) and body acceptance, manifesting femininity and experiencing an intimate relation with a partner in breast cancer patients. Psychiatr Pol 2018;52:859-72. doi: 10.12740/PP/91916

39. Jabłoński MJ, Mirucka B, Streb J, Słowik AJ, Jach R. Exploring the relationship between the body self and the sense of coherence in women after surgical treatment for breast cancer. Psychooncology 2019;28:54-60. doi: 10.1002/pon.4909

40. Jay M, Creelman B, Baliski C. Patient reported outcomes associated with surgical intervention for breast cancer. Am J Surg 2019;219:816-22. doi: 10.1016/j. amjsurg.2019.04.006

41. Kennedy F, Harcourt D, Rumsey N, White P. The psychosocial impact of ductal carcinoma in situ (DCIS): A longitudinal prospective study. Breast 2010;19:382-7. doi: 10.1016/j. breast.2010.03.024

42. Lagendijk M, van Egdom LSE, van Veen FEE, Vos EL, Mureau MAM, van Leeuwen N, et al. Patient-reported outcome measures may add value in breast cancer surgery. Ann Surg Oncol 2018;25:3563-71. doi: 10.1245/s10434-018-6729-6

43. Li S, Li L, Zheng H, Wang Y, Zhu X, Yang Y, et al. Relationship between multifaceted body image and negative affect among women undergoing mastectomy for breast cancer: a longitudinal study. Arch Womens Ment Heal 2018;21:681-8. doi: 10.1007/s00737-0180860-z

44. Luutonen S, Sintonen H, Stormi T, Salminen E. Health-related quality of life during adjuvant radiotherapy in breast cancer. Qual Life Res 2013/11/10. 2013;23:1363-9. doi: 10.1007/s11136-013-0554-y

45. Maharjan M, Thapa N, Adhikari RD, Petrini MA, Amatya KS. Quality of life of Nepalese women post mastectomy. Asian Pac J Cancer Prev 2018;19:1005-12. doi: 10.22034/ APJCP.2018.19.4.1005

46. Manganiello A, Hoga LAK, Reberte LM, Miranda CM, Rocha CAM. Sexuality and quality of life of breast cancer patients post mastectomy. Eur J Oncol Nurs 2011;15:16772. doi: 10.1016/j.ejon.2010.07.008

47. Martins JO de A, Santos AAP dos, Holanda JB de L, Trindade RFC da, Lima LKP. Sexualidade de mulheres submetidas à mastectomia: identificação das fases afetadas no ciclo da resposta sexual TT - Sexuality of women submitted to mastectomy: identification of phases affected in the sexual response cycle Sexualidad de mujeres submetida. Rev Pesqui (Univ Fed Estado Rio J, Online) 2020;12:67-72. doi: 10.9789/2175-5361.rpcfo. v12.7013

48. Metcalfe KA, Semple J, Quan ML, Vadaparampil ST, Holloway C, Brown M, et al. Changes in psychosocial functioning 1 year after mastectomy alone, delayed breast reconstruction, or immediate breast reconstruction. Ann Surg Oncol 2012;19:233-41. doi: 10.1245/s10434-011-1828-7

49. Moreira H, Canavarro MC. A longitudinal study about the body image and psychosocial adjustment of breast cancer patients during the course of the disease. Eur J Oncol Nurs 2010;14:263-70. doi: 10.1016/j.ejon.2010.04.001

50. Moreira JR, Neto MS, Pereira JB, Biasi T, Garcia EB, Ferreira LM. Sexualidade de mulheres mastectomizadas e submetidas à reconstrução mamária TT - Sexuality of women that suffered mastectomy and those who had been submitted to the mammary reconstruction. Rev Bras Mastologia 2010;20:177-82.

51. Munshi A, Dutta D, Kakkar S, Budrukkar A, Jalali R, Sarin R, et al. Comparison of early quality of life in patients treated with radiotherapy following mastectomy or breast 
conservation therapy: A prospective study. Radiother Oncol 2010;97:288-93. doi: 10.1016/j.radonc.2010.04.008

52. Mushtaq M, Naz F. Body image satisfaction, distress and resilience in women with breast cancer surgery: A within group study. J Postgrad Med Inst 2017;31:39-43.

53. Neto MS, Menezes MVA, Moreira JR, Garcia EB, Abla LEF, Ferreira LM. Sexuality after breast reconstruction post mastectomy. Aesthetic Plast Surg 2013;37:643-7. doi: 10.1007/s00266-013-0082-8

54. Ng SK, Hare RM, Kuang RJ, Smith KM, Brown BJ, Hunter-Smith DJ. Breast reconstruction post mastectomy: patient satisfaction and decision making. Ann Plast Surg 2016;76:640-4. doi: 10.1097/sap.0000000000000242

55. Nowicki A, Licznerska B, Rhone P. Evaluation of the quality of life of women treated due to breast cancer using amputation or breast conserving surgery in the early postoperative period. Pol J Surg 2015;87:174-80. doi: 10.1515/pjs-2015-0040

56. Núñez C, Navarro A, Cortés S, López J, Aguirre-Loaiza H, Trujillo C. Body image (BI) and coping strategies (CS): Analysis of medical and surgical characteristics in women diagnosed with breast cancer. Ter Psicol 2018;36:59-69. doi: 10.4067/S071848082018000200059

57. Öztürk D, Akyolcu N. Assessing sexual function and dysfunction in Turkish women undergoing surgical breast cancer treatment. Jpn J Nurs Sci 2016/04/05. 2016;13:220-8. doi: $10.1111 /$ jjns. 12106

58. Pegorare ABG de S, Silveira K da R, No APS, Barbosa SRM. Assessment of female sexual function and quality of life among breast cancer survivors who underwent hormone therapy $\mathrm{tt}$ - Avaliação da função sexual e da qualidade de vida de mulheres sobreviventes do câncer de mama submetidas a hormonioterapia. Mastology (Impr) 2017;27:237-44. doi: $10.5327 / \mathrm{Z} 259453942017000016166$

59. Prates ACL, Freitas-Junior R, Prates MFO, Veloso MF, Barros NM. Influence of body image in women undergoing treatment for breast cancer. Rev Bras Ginecol Obs 2017;39:175-83. doi: 10.1055/s-0037-1601453

60. Raggio GA, Butryn ML, Arigo D, Mikorski R, Palmer SC. Prevalence and correlates of sexual morbidity in long-term breast cancer survivors. Psychol Heal 2014;29:632-50. doi: 10.1080/08870446.2013.879136

61. Rahman MM, Hossain AFMA, Ahsan A, Monalisa NN, Rahman K, Azad SA. Moving beyond cancer: Immediate impact on the health-related quality of life of breast cancer patients after mastectomy. Bangladesh Med Res Counc Bull 2016;41:52-8. doi:10.3329/ bmrcb.v41i2.29974

62. Retrouvey H, Kerrebijn I, Metcalfe KA, O’Neill AC, McCready DR, Hofer SOP, et al. Psychosocial functioning in women with early breast cancer treated with breast surgery with or without immediate breast reconstruction. Ann Surg Oncol 2019;26:2444-51. doi: 10.1245/s10434-019-07251-9

63. Seara LS, Vieira RX, Pechorro PS. Sexual function and body image in mastectomized women. Rev Int Androl 2012;10:106-12. doi: 10.1016/S1698-031X(12)70063-8

64. Sherman KA, Woon S, French J, Elder E. Body image and psychological distress in nipple-sparing mastectomy: the roles of self-compassion and appearance investment. Psychooncology 2016;26:337-45. doi: 10.1002/pon.4138

65. Spatuzzi R, Vespa A, Lorenzi P, Miccinesi G, Ricciuti M, Cifarelli W, et al. Evaluation of social support, quality of life, and body image in women with breast cancer. Breast Care 2016;11:28-32. doi: 10.1159/000443493 
66. Streb J, Jabłoński MJ, Słowik A, Babczyk D, Jach R. Indications for sexology consultation in women after surgical treatment due to breast cancer. Ann Agric Env Med 2018;26:37984. doi: $10.26444 /$ aaem/89733

67. Sun Y, Kim SW, Heo CY, Kim D, Hwang Y, Yom CK, et al. Comparison of quality of life based on surgical technique in patients with breast cancer. Jpn J Clin Oncol 2013;44:227. doi: $10.1093 /$ jjco/hyt176

68. Słowik AJ, Jabłoński MJ, Michałowska-Kaczmarczyk AM, Jach R. Evaluation of quality of life in women with breast cancer, with particular emphasis on sexual satisfaction, future perspectives and body image, depending on the method of surgery. Psychiatr Pol 2017;51:871-88. doi: 10.12740/PP/OnlineFirst/63787

69. Telli S, Gürkan A. Examination of sexual quality of life and dyadic adjustment among women with mastectomy. Eur J Breast Heal 2020/01/09. 2020;16:48-54. doi: 10.5152/ ejbh.2019.4969

70. Tsai HY, Kuo RN, Chung KP. Quality of life of breast cancer survivors following breastconserving therapy versus mastectomy: A multicenter study in Taiwan. Jpn J Clin Oncol 2017;47:909-18. doi: 10.1093/jjco/hyx099

71. Wani S, Khan T, Teli M, Khan N, Mir L, Lone M, et al. Breast specific functional and symptom analysis in female breast cancer survivors. J Cancer Res Ther 2018;14:521-6. doi: 10.4103/0973-1482.165867

72. Wu TY, Chang TW, Chang SM, Lin YY, Wang JD, Kuo YL. Dynamic changes of body image and quality of life in breast cancer patients. Cancer Manag Res 2020;11:10563-71. doi: 10.2147/CMAR.S223314

73. Oliveira LB, Dantas ACLM, Paiva JC, Leite LP, Ferreira PHL, Abreu TMA. A feminilidade e sexualidade da mulher com câncer de mama. Rev Científica da Esc da Saúde / Univ Potiguar. 2013;3(1):43-53.

74. Santos DB, Vieira EM. Imagem corporal de mulheres com câncer de mama: Uma revisão sistemática da literatura. Cien Saude Colet 2011;16:2511-22. doi: 10.1590/S141381232011000500021

75. de Almeida TR, Guerra MR, Filgueiras MST. Repercussões do câncer de mama na imagem corporal da mulher: Uma revisão sistemática. Physis 2012;22:1003-29. doi: 10.1590/S0103-73312012000300009

76. Aureliano W de A. “... e Deus criou a mulher”: Reconstruindo o corpo feminino na experiência do câncer de mama. Estud Fem 2009;17:49-70. doi: 10.1590/S0104026X2009000100004

77. Didier F, Radice D, Gandini S, Bedolis R, Rotmensz N, Maldifassi A, et al. Does nipple preservation in mastectomy improve satisfaction with cosmetic results, psychological adjustment, body image and sexuality? Breast Cancer Res Trea. 2008;118:623-33. doi: 10.1007/s10549-008-0238-4

78. Palmeira CS, Santos LS, Silva SMB da, Mussi FC. Estigma percebido por mulheres com excesso de peso. Rev Bras Enferm 2020;73(4):e20190321. doi: 10.1590/0034-71672019-0321

79. Cesnik VM, Santos MA dos. Mastectomia e Sexualidade: Uma Revisão Integrativa. Psicol Reflex Crit 2012;339-49. doi:10.1590/S0102-79722012000200016

80. Vaziri S, Lotfi-Kashani F. Sexuality after breast cancer: need for guideline. Iran J Cancer Prev 2012;5:10-5.

81. Hart AM, Pinell-White X, Losken A. The psychosexual impact of postmastectomy breast reconstruction. Ann Plast Surg 2015;77:517-22. doi:10.1097/SAP.0000000000000665 
82. Gilbert E, Ussher JM, Perz J. Sexuality after breast cancer: a review. Maturitas. 2010;66:397-407. doi:10.1016/j.maturitas.2010.03.027

83. Santos DB, Santos MA dos, Vieira EM. Sexualidade e câncer de mama: Uma revisão sistemática da literatura. Saúde Soc 2014;23:1342-55. doi:10.1590/S010412902014000400018

84. Male DA, Fergus KD, Cullen K. Sexual identity after breast cancer: Sexuality, body image, and relationship repercussions. Curr Opin Support Palliat Care 2016;10:66-74. doi:10.1097/SPC.0000000000000184

85. Boswell EN, Dizon DS. Breast cancer and sexual function. Transl Androl Urol 2015;4(2):160-8. doi:10.3978/j.issn.2223-4683.2014.12.04

86. Chang YC, Chang SR, Chiu SC. Sexual Problems of Patients with Breast Cancer after Treatment: A Systematic Review. Cancer Nurs 2018;42:418-25. doi:10.1097/ NCC.0000000000000592

87. Simeão SF de AP, Landro ICR, De Conti MHS, Gatti MAN, Delgallo WD, De Vitta A. Qualidade de vida em grupos de mulheres acometidas de câncer de mama. Cien Saude Cole. 2013;18:779-88. doi: 10.1590/S1413-81232013000300024

88. Arndt V, Stegmaier C, Ziegler H, Brenner H. Quality of life over 5 years in women with breast cancer after breast-conserving therapy versus mastectomy: A population-based study. J Cancer Res Clin Oncol 2008;134:1311-8. doi: 10.1007/s00432-008-0418-y

89. Cordova LZ, Hunter-Smith DJ, Rozen WM. Patient reported outcome measures (PROMs) following mastectomy with breast reconstruction or without reconstruction: A systematic review. Gland Surg 2019;8:441-51. doi: 10.21037/gs.2019.07.02

90. Oliveira RR de, Mororais SS, Sarian LO. Efeitos da reconstrução mamária imediata sobre a qualidade de vida de mulheres mastectomizadas. Rev Bras Ginecol Obs 2010;32:602-8 doi: 10.1590/S0100-72032010001200007 